\title{
Orthodontically Relevant Manifestations in People with Rare Diseases
}

\author{
Marcel Hanisch ${ }^{a, c} \quad$ Lale Hanisch $^{b} \quad$ Johannes Kleinheinz ${ }^{a} \quad$ Gholamreza Danesh $^{b}$ \\ Korbinian Benz ${ }^{c}$ Joachim Jackowski ${ }^{c}$ \\ ${ }^{a}$ Research Unit Rare Diseases with Orofacial Manifestations (RDOM), Department of Cranio-Maxillofacial Surgery, \\ University Hospital Münster, Münster, Germany; ${ }^{b}$ Department of Orthodontics, School of Dentistry, Faculty of \\ Health, Witten/Herdecke University, Witten, Germany; ' Department of Oral Surgery and Dental Emergency Care, \\ School of Dentistry, Faculty of Health, Witten/Herdecke University, Witten, Germany
}

\section{Significance of the Study}

- In the future, digital databases will gain in importance especially in the diagnosis of rare diseases. The orthodontist can ascertain several rare diseases on the basis of typical symptoms, such as oligodontia or dysgnathia, after which the patient can get more detailed information on the digital database.

\section{Keywords}

Rare diseases · Orofacial manifestations · Oral medicine · Orthodontics $\cdot$ Interdisciplinary dentistry

\footnotetext{
Abstract

Background: Approximately 15\% of all rare diseases occur with orofacial manifestations. Symptoms and manifestations of relevance to orthodontists represent a considerable proportion of these diseases and require appropriate strategies for their treatment. This article provides an overview of the orthodontically relevant manifestations of rare diseases. Material and Methods: Overall, 3,639 rare diseases listed at the Orphanet, OMIM or Pubmed database were evaluated for orofacial manifestations. All rare diseases which were indicated with at least one orofacial manifestation were recorded in a database for rare diseases with orofacial manifestations called "ROMSE," which was developed by the authors. All the rare diseases were analysed with regard to
}

orthodontically relevant orofacial manifestations, such as dysgnathia, changes in the number of teeth, failures of eruption, pathologies of bone metabolism or orofacial clefts. For all rare diseases with orthodontic relevance, an exact analysis was undertaken. Results: The orthodontically relevant orofacial manifestation termed dysgnathia is described in 151 of 535 identified rare diseases (28.2\%). In these 151 rare diseases, 15 different subforms of dysgnathia, in the sense of skeletal misdevelopments of the jaws but without dental abnormalities, were described. Also changes in the number of teeth $(17.9 \%)$, orofacial clefts $(27.6 \%)$, failures of eruption $(8.4 \%)$ and pathologies of the bone $(2.1 \%)$ were described. Conclusions: Orthodontics play an important role in the diagnosis and treatment of orofacial manifestations in rare diseases. Databases such as ROMSE are a first step toward providing valid information in publicly accessible databases.

(C) 2019 The Author(s)

Published by S. Karger AG, Basel

\section{KARGER}

E-Mail karger@karger.com www.karger.com/mpp

\section{Karger Published by S. Karger AG, Basel Open access}

This is an Open Access article licensed under the Creative Commons Attribution-NonCommercial-4.0 International License (CC BY-NC) (http://www.karger.com/Services/OpenAccessLicense), applicable to the online version of the article only. Usage and distribution for commercial purposes requires written permission.
Marcel Hanisch

Research Unit Rare Diseases with Orofacial Manifestations (RDOM)

Department of Cranio-Maxillofacial Surgery, University Hospital Münster

Albert-Schweitzer-Campus 1, Gebäude W 30

DE-48149 Münster (Germany)

E-Mail marcel.hanisch@ukmuenster.de 


\section{Introduction}

Around 4 million people in Germany are affected by various diseases [1]. Studies have shown that approximately $15 \%$ of all rare diseases occur with orofacial manifestations [2-4]. Symptoms and manifestations of relevance to orthodontists represent a considerable proportion of these diseases and require appropriate strategies for their treatment [5]. Often, the cases treated are so comprehensive and complex that an interdisciplinary treatment plan becomes necessary [5]. The symptoms that are relevant for orthodontists are dysgnathia, changes in the number of teeth (anodontia, hypodontia, oligodontia), cleft anomalies and bone diseases such as cherubism [6]. On average, a rare disease is present for 7 years before it is correctly diagnosed [7].

According to a definition given by the European Union $(\mathrm{EU})$, a disease is classified as "rare" when fewer than 1 in 2,000 people is affected by it. This definition applies to at least 30 million people in the 28 member states of the EU [8]. Since 2009, rare diseases in the EU have become the focus of public attention after the Council of the EU called upon member states to draw up plans and strategies for rare diseases at the appropriate level. These measures aim to ensure proper medical care for those affected. This should include diagnosis, treatment and rehabilitation measures [9]. For member states, the aim was to establish and accept a plan in this field by the end of 2013. Alongside this, results of a study commissioned by the German Ministry of Health were published in 2009 in which measures were presented to improve the situation relating to the health of people with rare diseases in Germany [10]. This report assessed the importance of rare diseases as being considerable. Among other aspects, research work was accorded a very high level of importance for the future care of patients with rare diseases. Moreover, the report considered it appropriate to have a "National Plan of Action for People with Rare Diseases" as drawn up by a National Action League. In October 2010 in Germany, the National Action League for People with Rare Diseases was subsequently set up with the aim of putting into practice the recommendations of the European Council. Finally, in 2013, the German Cabinet decided on a National Plan of Action for People with Rare Diseases for Germany, which ends in 2018. This plan comprises 7 fields of action and a total of 52 proposals [11]. The demands include the provision of sources of information and compiling epidemiological population-based patient registers [11].

Against this political background, a database for rare diseases with orofacial manifestations was first set up in 2013 [12]. The purpose of this article is to provide an overview of the orthodontically relevant manifestations of rare diseases described in Orphanet [13], OMIM [14],

Fig. 1. Subforms of dysgnathia described in the recorded rare diseases $(n)$.

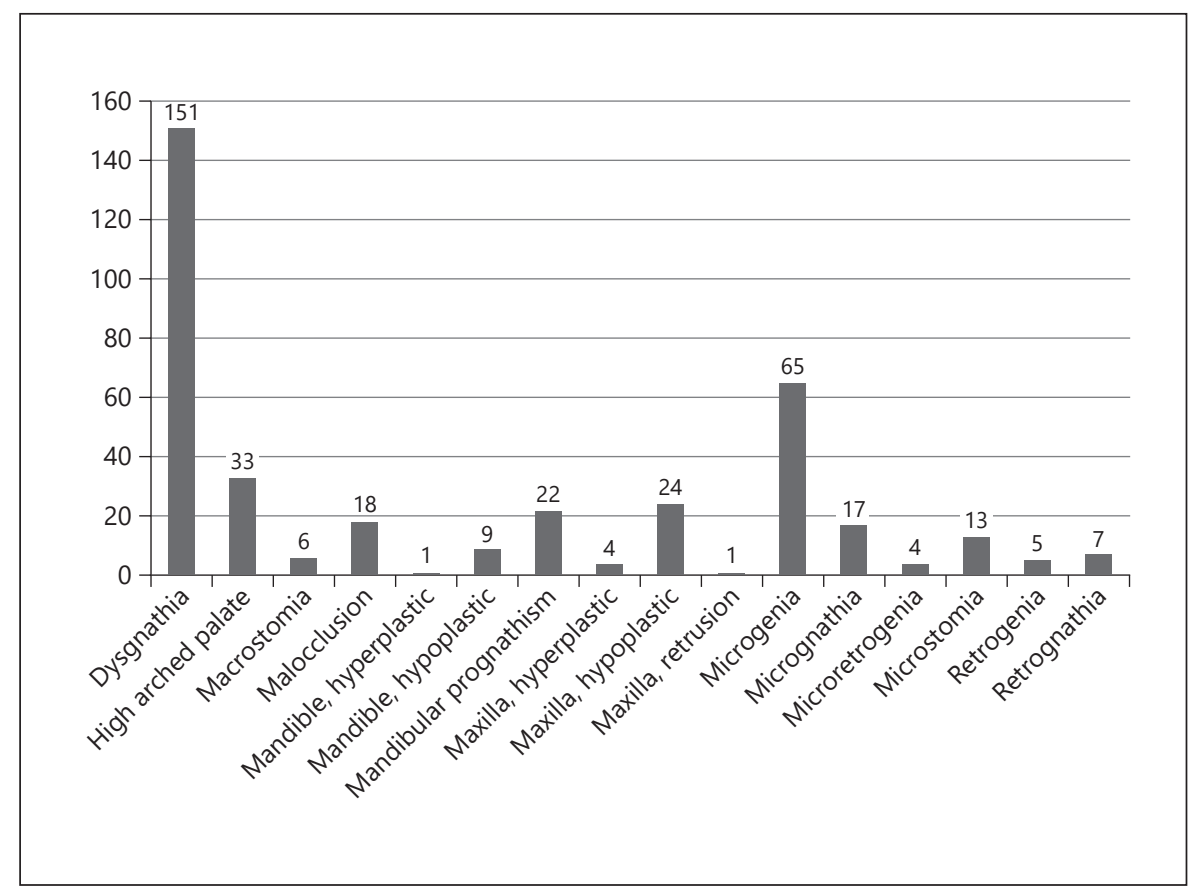




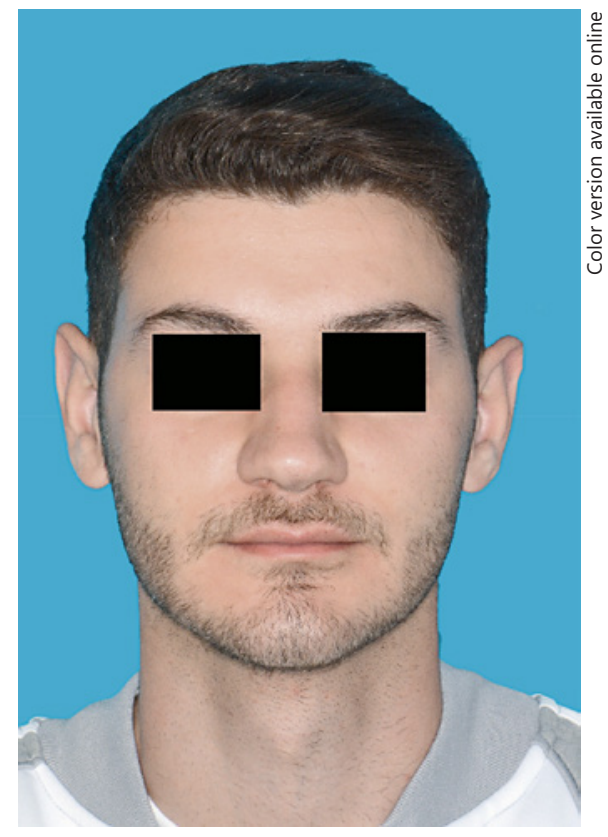

Fig. 2. A 21-year-old male patient with odonto-onychodermal dysplasia. Despite oligodontia he was initially diagnosed at the age of 20 years.

PubMed [15] and the ROMSE [16] database, which was developed by the authors based on these data, and to analyse them and present the problems associated with the correct diagnosis of rare diseases.

\section{Materials and Methods}

The ethical approval for this study was obtained from the ethical review committee (ref. No. 2017-374-f-N), Ethikkommission der Ärztekammer Westfalen-Lippe und der Westfälischen Wilhelms-Universität, Münster, Germany. Overall 3,639 rare diseases listed at the Orphanet Classification of Rare Diseases [17] were evaluated for orofacial manifestations in the Orphanet [13], OMIM [14] and Pubmed [15] databases between November 2012 and January 2018. All rare diseases indicated with at least one orofacial manifestation were incorporated in the specialized database for Rare Diseases with Orofacial Manifestations "ROMSE" (http:// romse.org), which was developed by the authors $[12,16]$. All the recorded rare diseases were analysed with regard to orthodontically relevant orofacial manifestations, such as dysgnathia, changes in the number of teeth, failures of eruption, pathologies of bone metabolism or orofacial clefts. For all rare diseases with orthodontic relevance, such as dysgnathia and the classification of the various forms that it takes, an exact analysis was undertaken.

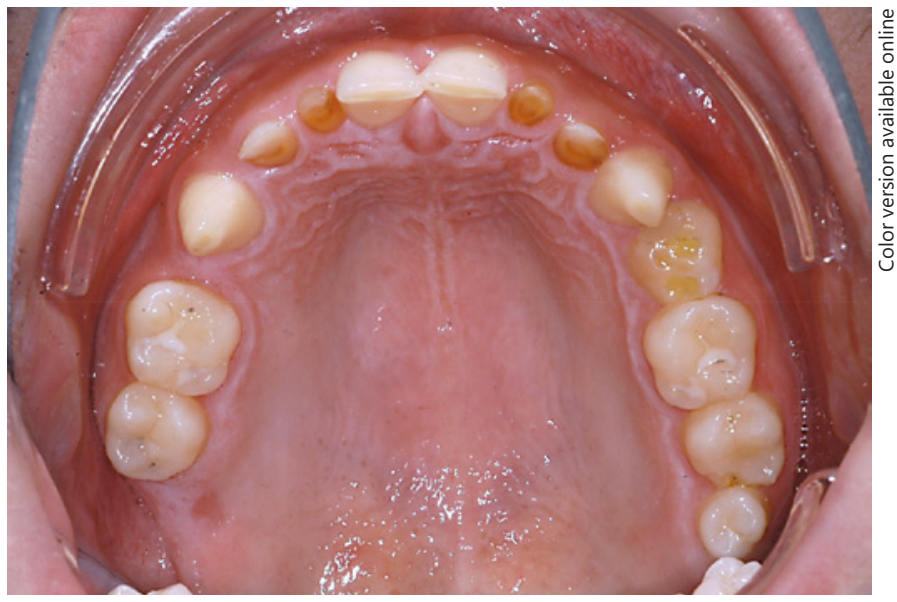

Fig. 3. A 21-year-old male patient with odonto-onychodermal dysplasia. Despite oligodontia he was initially diagnosed at the age of 20 years.

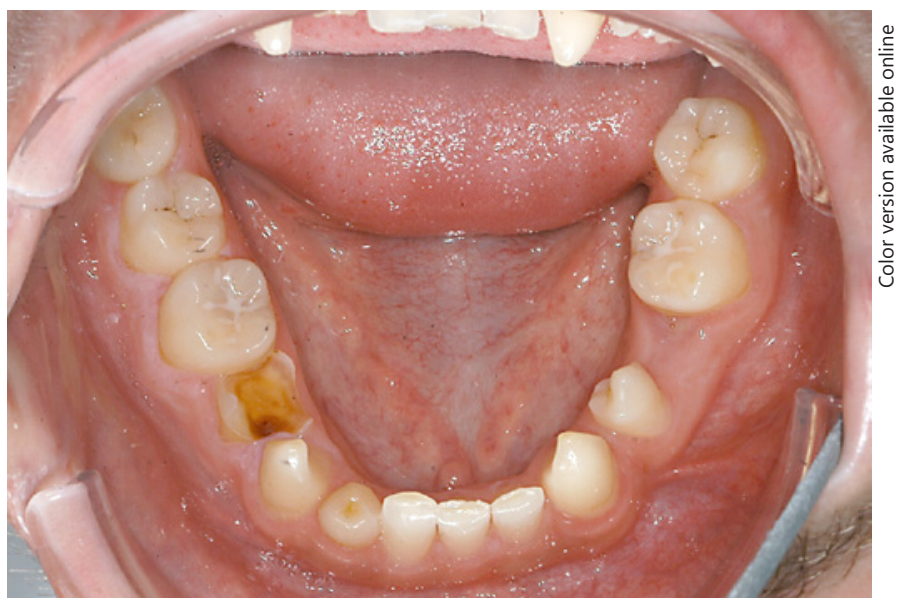

Fig. 4. A 21-year-old male patient with odonto-onychodermal dysplasia. Despite oligodontia he was initially diagnosed at the age of 20 years.

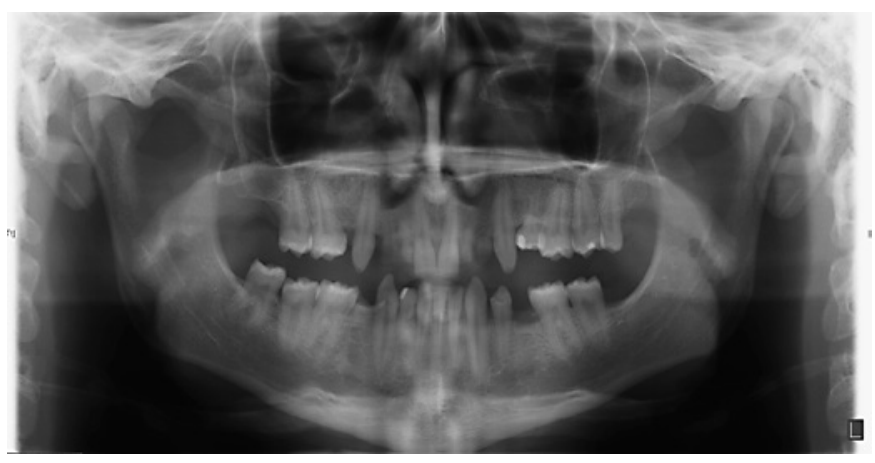

Fig. 5. A 21-year-old male patient with odonto-onychodermal dysplasia. Despite oligodontia he was initially diagnosed at the age of 20 years. 


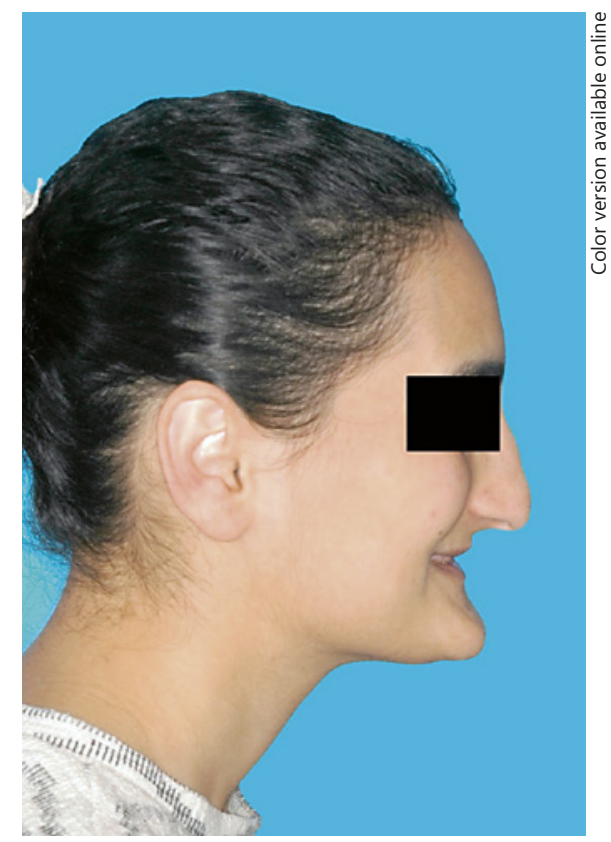

Fig. 6. A 29-year-old female patient with odonto-onychodermal dysplasia. Despite dysgnathia and oligodontia she was initially diagnosed at the age of 29 years.

\section{Results}

Overall 535 rare diseases with orofacial manifestations had been recorded and could be incorporated in the specialized database ROMSE. The orthodontically relevant orofacial manifestation termed dysgnathia is described in 151 of these 535 identified rare diseases (28.2\%). Under the main category "dysgnathia," in the sense of skeletal misdevelopments of the upper or lower jaw but without dental abnormalities, 15 subforms were described in these 151 rare diseases. These include among others: microgenia $(n=65)$, micrognathia $(n=17)$, high arched palate $(n=33)$, mandibular prognathism $(n=22)$, retrognathia $(n=7)$ or hyperplasia in the maxilla $(n=4)$. Figure 1 provides an overview of the subforms of dysgnathia described in the recorded rare diseases. Dental abnormalities comprise subforms including failures of eruption (8.4\%) such as tooth retentions $(n=13)$, dentitio tarda $(n=30)$ or dentitio praecox $(n=2)$. Changes in the number of teeth are described in a total of 96 of the rare diseases $(17.9 \%)$ and these concern hyperdontia $(n=9)$, hypodontia $(n=59)$, oligodontia $(n=$ $20)$, anodontia $(n=6)$ or hyperhypodontia $(n=2)$. Further orthodontically relevant orofacial manifestations described in rare diseases are cleft lips and palates in 27.6\% $(n=148)$ and pathologies of the bone in $2.1 \%(n=11)$.

Orthodontical Manifestations in Rare

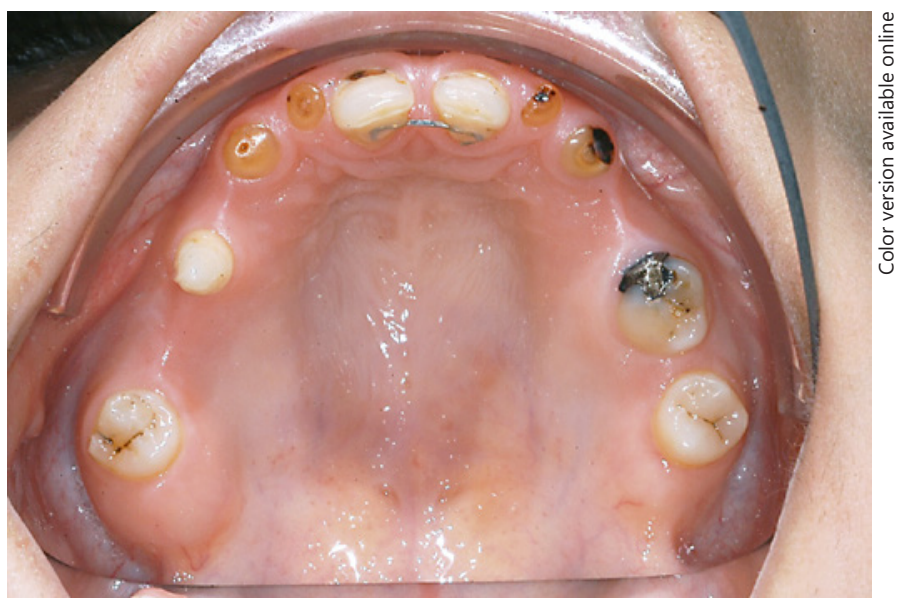

Fig. 7. A 29-year-old female patient with odonto-onychodermal dysplasia. Despite dysgnathia and oligodontia she was initially diagnosed at the age of 29 years.

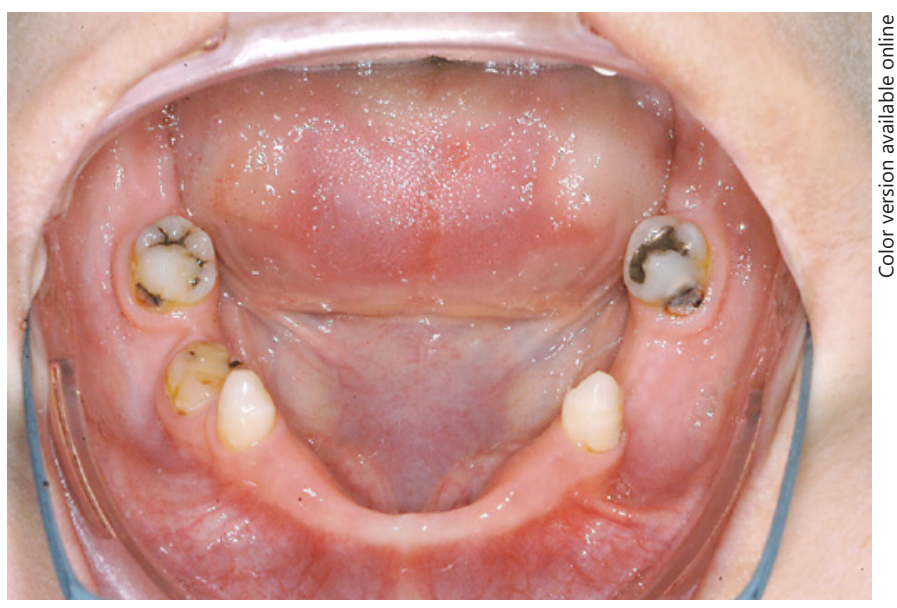

Fig. 8. A 29-year-old female patient with odonto-onychodermal dysplasia. Despite dysgnathia and oligodontia she was initially diagnosed at the age of 29 years.

\section{Discussion}

The results presented above underline the high proportion of orofacial manifestations that occur in rare diseases and that can be categorized under "Orthodontics." Dysgnathia, for example, is described in almost one third of the rare diseases with orofacial manifestations. If the changes in the number of teeth are added, their proportion rises even further. In many cases, however, the orofacial manifestations in rare diseases have not been described by dentists or orthodontists but are based on

Med Princ Pract 2019;28:216-221

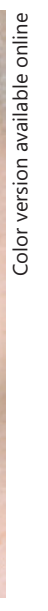




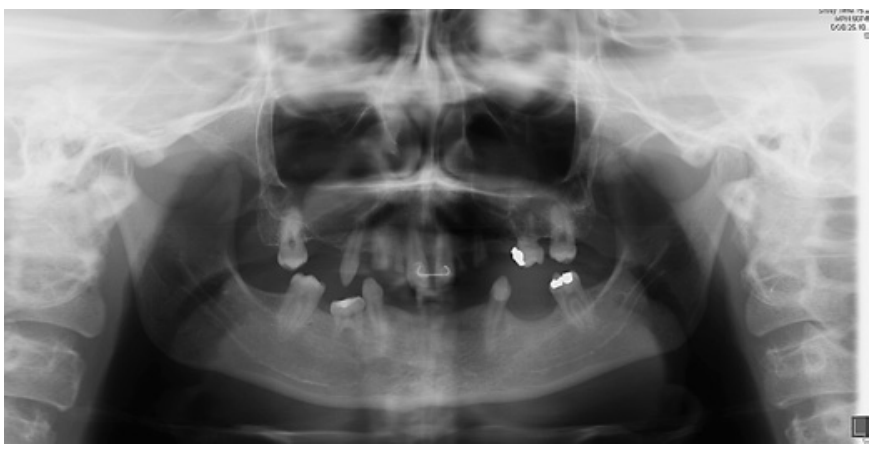

Fig. 9. A 29-year-old female patient with odonto-onychodermal dysplasia. Despite dysgnathia and oligodontia she was initially diagnosed at the age of 29 years.

medical or genetic publications [12]. This is attributable to the scarcity, or even lack, of publications relating to dental/orthodontic practice or oral surgery, and it has resulted in terminology for orofacial findings that is sometimes incorrect. Thus, in the case of rare diseases with no recorded orthodontic findings, no assumptions can be made with any certainty as to whether, for example, the disease involves a genuine mandibular prognathism or a maxillary retrognathism. We suggest that a structured standardized recording should be undertaken in collaboration with university hospitals or within the "European Reference Networks" [18].

On average, a rare disease is present for 7 years before it is correctly diagnosed [7], whereas oral manifestations can serve as an important indicator of the underlying disease $[19,20]$. Especially in patients with orthodontically relevant symptoms, such as dysgnathia or oligodontia, these not only can give a clue to the underlying disease, but also indicate serious impact on the oral health-related quality of life [21]. Research has also shown that patients with syndromic oligodontia which had not been linked to a rare disease in the first place reported substantially worse outcomes [22]. Especially when it comes to the combination of the symptoms oligodontia and dysgnathia, as found for example in odonto-onychodermal dysplasia, the orthodontist has an important role to play to recognize this in the context with a rare disease (Fig. 2-10). In particular, these externally otherwise inconspicuous forms of ectodermal dysplasia are often not recognized, resulting in years of uncertainty for the persons concerned [22].

Dental and medical background information, in particular concerning orofacial manifestations, plus material for further reading, can be retrieved via the ROMSE da-

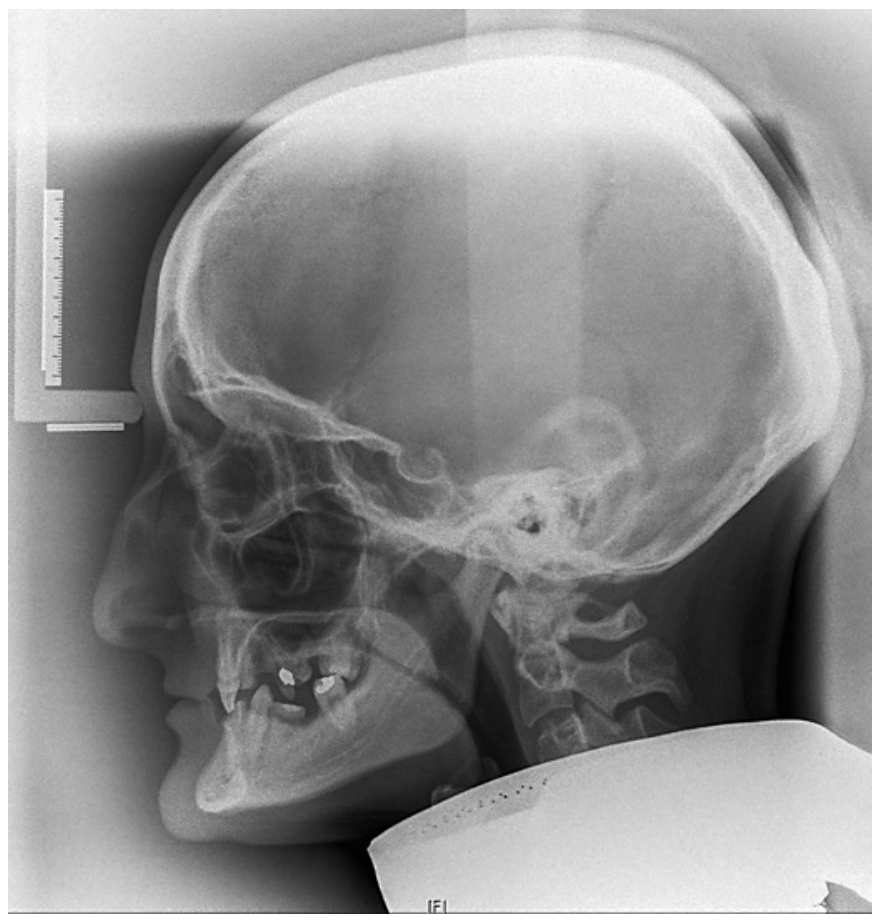

Fig. 10. A 29-year-old female patient with odonto-onychodermal dysplasia. Despite dysgnathia and oligodontia she was initially diagnosed at the age of 29 years.

tabase mentioned above, although its limitations have to be taken into account. At present, this database is available only in German. An English version is currently being set up so that the database can be used globally. In the future, however, computer-based systems will offer health professionals passive decision support. On the basis of symptoms, structured, weighted lists of possible differential diagnoses are presented to the user. By using such tools diagnostic quality could be enhanced and diagnostic findings accelerated [23]. Databases, such as ROMSE, are thus a first step to provide the necessary data for the construction of an intelligent software system [23]. Furthermore, the demand for freely accessible information is high. This is shown by the large number of websites on the Internet run by patients' organizations [24]. Therefore, databases like ROMSE should be available as a source of information for patients and their relatives.

The orofacial manifestations of rare diseases, such as dysgnathia or changes in the number of teeth (e.g. oligodontia, hypodontia), presented here make clear the important role that orthodontics play in the early diagnosis and treatment of rare diseases. Genetic diseases such as ectodermal dyplasias with WNT 10A mutations can 
manifest themselves with various phenotypes [25] (Fig. 2-10). In some cases, orodental anomalies such as oligodontia become apparent only later as part of a change in dentition. Orthodontists may then be contacted as specialists who will correctly classify the symptoms and arrange for further analyses to be carried out in the form of genetic examination. This underlines their importance in early diagnoses. A further task resulting from this initial consultation is the subsequent treatment that often requires interdisciplinary collaboration with other disciplines of dentistry [5]. Furthermore, it seems to be important that not just dentists, but also medical doctors should be taught in oral health education [26] and public health systems should implicate oral health programmes [27] in order to improve oral health-related quality of life.

\section{Conclusions}

Orthodontics play an important role in the diagnosis and treatment of orofacial manifestations of rare diseases. Orthodontically relevant orofacial manifestations like dysgnathia or reduced number of teeth appear in a relevant proportion of rare diseases with orofacial manifestations. Orthodontists have not yet produced structured findings relating to such rare diseases, of which there are many. Databases, such as ROMSE, are a first step toward providing valid information in publicly accessible databases.

\section{Disclosure Statement}

The authors declare no conflict of interests.

\section{References}

1 German Federal Ministry of Health. Seltene Erkrankungen [cited 2017 Feb 9]. Available from: http://www.bmg.bund.de/themen/ praevention/gesundheitsgefahren/seltene-erkrankungen.html

2 Johns Hopkins University. OMIM - online catalog of human genes and genetic disorders [cited 2017 Jan 22]. Available from: https:// www.ncbi.nlm.nih.gov/omim

3 Jackowski J, Hanisch M. Orofacial manifestations in 2,006 rare diseases - a preliminary systematic review of the literature. German J Dent Oral Med. 2012;67:D10.

4 Hennekam RC, Allanson JE, Krantz ID, et al. Gorlin's syndromes of the head and neck. 5th ed. Oxford: Oxford University Press; 2010.

5 Hanisch M, Kleinheinz J, Hanisch L, et al. ROMSE - a webbased register for orofacial manifestations in people with rare diseases. Eur Orthodont. 2016;38:e2-229.

6 Abela S, Cameron M, Bister D. Orthodontic treatment in cherubism: an overview and a case report. Aust Orthod J. 2014 Nov;30(2):214-20.

7 Schmitt-Sausen N. Tag der Seltenen Erkrankungen: Mehr Aufmerksamkeit für Waisenkinder der Medizin. Dtsch Ärztebl 2010;107:A-430/B-381/C-373.

8 Regulation (EC) No 141/2000 of the European Parliament and of the Council of 16 December 1999 on orphan medical products [cited 2017 Feb 9]. Available from: http:// ec.europa.eu/health/files/eudralex/vol-1/ reg_2000_141_cons-2009-07/reg_2000_141_ cons-2009-07_en.pdf

9 The Council of the European Union. Council recommendation of 8 June 2009 on an action in the field of rare diseases (2009/C 151/02) [cited $2017 \mathrm{Feb} 9$ ]. Available from: http://eurlex.europa.eu/LexUriServ.do?uri=OJ:C:2009: 151:0007:0010:EN:PDF
10 German Federal Ministry of Health. Measures to improve the health situation of patients with rare diseases [cited 2017 Jan 20]. Available from: http://www.bmg.bund.de/fileadmin/dateien/Downloads/Forschungsberichte/110516_Forschungsbericht_Seltene_ Krankheiten.pdf

11 National Action League for People with Rare Diseases. National plan of action for people with rare diseases: action fields, recommendations, proposed actions. German Federal Ministry of Health, German Federal Ministry of Education and Research, Alliance for Chronic Rare Diseases 2013 [cited 2017 Feb 9]. Available from: http://www.namse.de/english.html

12 Hanisch M, Hanisch L, Benz K, Kleinheinz J, Jackowski J. Development of a database to record orofacial manifestations in patients with rare diseases: a status report from the ROMSE (recording of orofacial manifestations in people with rare diseases) database. Br J Oral Maxillofac Surg. 2017 Jun;55(5):500-3.

13 Orphanet [cited 2018 Mar 2]. Available from: http://www.orpha.net

14 Online Mendelian Inheritance in ManOMIM [cited 2018 Apr 19]. Available from: https://www.omim.org

15 PubMed [cited 2018 Feb 22]. Available from: https://www.ncbi.nlm.nih.gov

16 Registration database for rare diseases with orofacial manifestations - ROMSE [cited 2018 Jan 22]. Available from: http://romse.org

17 Orphanet list of rare diseases and synonyms [cited 2017 Aug 22]. Available from: http:// www.orpha.net/orphacom/cahiers/docs/DE/ Verzeichnis_der_seltenen_Krankheiten_in_ alphabetischer_Reihenfolge.pdf

18 Héon-Klin V. European Reference networks for rare diseases: what is the conceptual framework? Orphanet J Rare Dis. 2017 Aug;12(1):137.
19 Hanisch M, Fröhlich LF, Kleinheinz J. Gingival hyperplasia as first sign of recurrence of granulomatosis with polyangiitis (Wegener's granulomatosis): case report and review of the literature. BMC Oral Health. 2016 Aug;17(1):33.

20 Hanisch M, Jung S, Kleinheinz J. [Identification of rare diseases in the oral cavity]. Internist (Berl). 2018 Sep;59(9):972-80. German.

21 Wiemann S, Frenzel Baudisch N, Jordan RA Kleinheinz J, Hanisch M. Oral Symptoms and oral health-related quality of life in people with rare diseases in germany: A Cross-Sectional Study. Int J Environ Res Public Health. 2018 Jul;15(7):E1493.

22 Hanisch M, Bohner L, Jung S, Kleinheinz J. Seltene Erkrankungen mit implantologischem Therapiebedarf: ektodermale Dysplasien. Implantologie. 2018;26:157-66.

23 Müller T, Jerrentrup A, Schäfer JR. [Computer-assisted diagnosis of rare diseases]. Internist (Berl). 2018 Apr;59(4):391-400. German.

24 Pauer F, Litzkendorf S, Göbel J, Storf H, Zeidler J, Graf von der Schulenburg JM. Rare Diseases on the Internet: an assessment of the quality of online information. J Med Internet Res. 2017 Jan;19(1):e23.

25 Tardieu C, Jung S, Niederreither K, et al. Dental and extra-oral clinical features in $41 \mathrm{pa}-$ tients with WNT10A gene mutations: a multicentric genotype-phenotype study. Clin Genet. 2017 Nov;92(5):20(Jan):477-86.

26 Park SE, Donoff RB, Saldana F. The impact of integrating oral health education into a medical curriculum. Med Princ Pract. 2017;26(1): 61-5.

27 Alsumait A, ElSalhy M, Amin M. Long-term effects of school-based oral health program on oral health knowledge and practices and oral health-related quality of life. Med Princ Pract. 2015;24(4):362-8. 